\title{
ANALISANDO NARRATIVAS SOBRE A UTILIZAÇÃO DO LIVRO "OS 15 ANOS DE MARIANA” EM UMA ESCOLA MUNICIPAL DO RIO GRANDE, RS
}

\author{
ANALIZANDO NARRATIVAS SOBRE LA UTILIZACIÓN DEL LIBRO "OS 15 ANOS \\ DE MARIANA" EN UNA ESCUELA MUNICIPAL DEL RIO GRANDE, RS
}

\author{
ANALYZING NARRATIVES ON THE USE OF THE BOOK "OS 15 ANOS DE \\ MARIANA" IN A MUNICIPAL SCHOOL OF RIO GRANDE, RS
}

\author{
Taina Guerra CHIMIESKI ${ }^{1}$ \\ Raquel Pereira QUADRADO ${ }^{2}$
}

RESUMO: O livro intitulado "Os 15 anos de Mariana: um convite a outras aprendizagens sobre corpos", possibilita o entendimento de que os corpos são construções biossociais. O objetivo deste artigo é analisar narrativas de professoras de uma escola de Ensino Fundamental no município do Rio Grande, RS que utilizaram este material para desenvolver um projeto de ensino. As narrativas foram produzidas a partir de um grupo focal, com as professoras envolvidas. Para a produção e análise destes dados utilizamos a investigação narrativa, que nos permitiu apontar que o livro foi bem acolhido pelo grupo pesquisado e que o trabalho desenvolvido a partir deste possibilitou que os/as estudantes produzissem um conhecimento que estabelece relação com o seu cotidiano.

PALAVRAS-CHAVE: Corpos. Currículo. Ensino. Livro paradidático.

RESUMEN: El libro titulado "Os 15 anos de Mariana: um convite a outras aprendizagens sobre corpos", posibilita el entendimiento de que los cuerpos son construcciones biossociales. El objetivo de este artículo es analizar narrativas de profesoras de una escuela de Enseñanza Fundamental en el municipio do Rio Grande, RS que utilizaron este material para desarrollar un proyecto de enseñanza. Las narrativas fueron producidas a partir de un grupo focal, con las profesoras involucradas. Para la producción y análisis de estos datos utilizamos la investigación narrativa, que nos permitió apuntar que el libro fue bien acogido por el grupo investigado y que el trabajo desarrollado a partir de éste, posibilitó que los/las estudiantes producieran un conocimiento que establece relación con su cotidiano.

PALABRAS CLAVE: Cuerpos. Currículo. Enseñanza. Libro paradidático.

ABSTRACT: The book entitled "Os 15 anos de Mariana: um convite a outras aprendizagens

${ }^{1}$ Universidade Federal do Rio Grande (FURG), Rio Grande - RS - Brasil. Mestre em Educação. Programa de Pós-Graduação em Educação. ORCID: <https://orcid.org/0000-0002-4667-8197>. E-mail: taina.bio@hotmail.com

${ }^{2}$ Universidade Federal do Rio Grande (FURG), Rio Grande - RS - Brasil. Pós- Doutora em Educação em Ciências pela Escola Superior de Educação do Instituto Politécnico de Coimbra. Instituto de Educação. Programa de Pós-Graduação em Educação e Programa de Pós-Graduação em Educação em Ciências. ORCID: <https://orcid.org/0000-0003-0205-7783> E-mail: raquelquadrado@ hotmail.com 
sobre corpos" enables the understanding that the bodies are biosocial constructions. The aim of this paper is to analyze the narratives made by teachers of a municipal school in the city of Rio Grande, RS that used this material to develop a teaching project. The narratives were produced from a focus group, with the teachers that was involved. For the production and analysis of data we use the narrative research, which allows us to point out that the book was well received by the group studied and that the work from this, enabled students to produce knowledge that establishes relationship with their daily lives.

KEYWORDS: Bodies. Curriculum. Teaching. Complementary textbook.

\section{Introdução}

O presente artigo encontra-se ancorado no campo dos Estudos Culturais, na sua perspectiva pós-estruturalista. Temos por objetivo analisar como o livro 3 paradidático “Os 15 anos de Mariana: um convite a outras aprendizagens sobre corpos ${ }^{4}$ " foi utilizado em uma escola de Ensino Fundamental, pertencente à rede Municipal de Ensino da cidade do Rio Grande, RS. Para tal, utilizamos a metodologia de investigação narrativa na produção e na análise dos dados. Faz parte da dissertação de mestrado cujo objetivo é analisar os efeitos do livro nas práticas docentes.

Entendemos que o corpo é produzido não apenas pela materialidade biológica, mas também pelos múltiplos discursos que o interpelam. Dessa forma, é uma construção biossocial, produzido, transformado e reconfigurado através das práticas sociais e dos discursos presentes na sociedade. Entender o corpo como uma construção cultural e social não é negar a sua materialidade biológica, afinal, somos também produzidos por ela, mas perceber que não somos apenas um conjunto de ossos e vísceras. De acordo com Elenita Silva, o corpo apresentado na escola é "um corpo fragmentado, retirado dos espaços culturais que ocupa, ou seja, um corpo vazio" (2010, p. 21). Assim, ao utilizar uma abordagem que desconsidera os demais discursos envolvidos na produção dos corpos, a escola acaba por legitimar um modelo de corpo que é fixo, estável, que não possui desejos nem vontades, inalterado, bem diferente de como são os nossos corpos, como aponta Guacira Louro: "o corpo se altera com a passagem do tempo, com a doença, com mudanças de hábitos alimentares e de vida, com

${ }^{3}$ A fim de tornar a leitura mais fluida em referências futuras nos referiremos ao livro "Os 15 anos de Mariana: um convite a outras aprendizagens sobre corpos" como o livro de Mariana.

${ }^{4}$ RIBEIRO, Paula Regina Costa; LONGARAY, Deise Azevedo (Org.). Os 15 anos de Mariana: um convite a outras aprendizagens sobre corpos. Rio Grande: FURG, 2013. 144p. Produzido no contexto do projeto Ciência, Universidade e Escola investindo em Novos Talentos, a obra propõe abordar o corpo como uma construção biossocial. A partir de uma parceria firmada entre a Prefeitura Municipal do Rio Grande, RS e a Universidade Federal do Rio Grande - FURG, um kit contendo trinta (30) exemplares do livro foi distribuído a todas as escolas de ensino fundamental pertencentes à rede municipal de educação. 
possibilidades distintas de prazer ou com novas formas de intervenção médica e tecnológica" (2013, p. 14).

O corpo está em constante processo de produção, é plural, moldável, único e assim "torna-se, então, a arena onde acontecem discursos e conflitos simbólicos, políticos, culturais, étnicos, históricos, religiosos e econômicos, refletindo as questões do nosso tempo" (BRUNS; DAVI, 2016, p. 436). Ao entendê-lo dessa maneira, cabe pensar possibilidades de abordagem que propiciem aos corpos serem vistos desse modo no espaço escolar. Nesse sentido, problematizar a construção social, cultural, biológica, histórica e discursiva dos corpos é a proposta do livro de Mariana. Partindo de um tema comum presente no universo adolescente, a festa de 15 anos, o livro envolve o/a ${ }^{5}$ leitor/a nos dramas, alegrias, problemas e conflitos vivenciados pela protagonista Mariana e sua rede de amigos/as e familiares.

Ao longo da história, assuntos como o consumo de álcool, Alzheimer, dietas, relações sexuais, tabagismo, doenças respiratórias e hormônio do crescimento vão sendo introduzidos ao enredo de forma contextualizada, fazendo parte do cotidiano das personagens. A inserção de tais temas abre espaço para a discussão do corpo como um conjunto integrado, mostrando que os órgãos trabalham em conjunto, e possibilitando que o/a leitor/a perceba os múltiplos processos que ocorrem de forma simultânea, juntamente aos aspectos socioculturais que também são responsáveis por produzirem efeitos nos corpos.

A utilização do livro em sala de aula amplia a discussão sobre os corpos, ao possibilitar outros olhares para o tema, além do biológico. Ainda, colabora na promoção de um ensino que estabelece relação com o cotidiano dos/as estudantes, que traz temas presentes em seu dia-a-dia e que aproxima o conhecimento científico dos demais saberes adquiridos por eles/as. Logo, acreditamos que as atividades desenvolvidas a partir da obra mencionada apresentam relevância para os estudos acerca do ensino do corpo, justificando a produção desta pesquisa.

Neste artigo, nossa proposta é analisar as narrativas produzidas em um grupo focal realizado com oito (8) professoras de uma escola municipal localizada na cidade do Rio Grande, RS, as quais desenvolveram um projeto interdisciplinar a partir do livro de Mariana. Para tal, dividimos o texto em alguns momentos: de início, problematizamos como os corpos vêm sendo abordados nos currículos escolares. Em um segundo momento, evidenciamos como os dados narrativos foram produzidos e apresentamos o livro de Mariana. Em seguida, apontamos algumas análises com base nas narrativas das professoras, desenvolvidas a partir

\footnotetext{
${ }^{5}$ A partir de uma demarcação política utilizaremos neste texto a referência aos gêneros masculino e feminino.
} 
do grupo focal. Por fim, tecemos algumas considerações.

\section{Corpo e currículo escolar}

A escola e o currículo estão intrinsecamente ligados ao desenvolvimento dos sujeitos. Os currículos escolares, ao eleger certos conhecimentos como legítimos e a estes oportunizar um espaço privilegiado de discussões, não o faz de forma inocente, neutra ou desinteressada, conforme nos apontam Antônio Moreira e Tomaz Tadeu da Silva:

O currículo não é elemento inocente e neutro de transmissão desinteressada do conhecimento social. O currículo está implicado em relações de poder, o currículo transmite visões sociais particulares e interessadas, o currículo produz identidades individuais e sociais particulares. O currículo não é um elemento transcendente e atemporal - ele tem uma história, vinculada a formas específicas e contingentes de organização da sociedade e da educação (MOREIRA; SILVA, 2000, p. 7-8).

Entender que os currículos escolares são frutos de uma construção sociocultural nos possibilita questionar a presença e o enfoque conferido a certos temas e a ausência de outros. No caso do corpo, é comum perceber que as abordagens utilizadas remetem ao ensino pautado no viés biológico, fragmentado, em que o corpo é apresentado sem sexo, anônimo, sem etnia, sem identidade, deslocado de um contexto cultural, político e histórico. Dessa maneira, os corpos tornam-se estáticos, universais, imutáveis, sem história, deslocados de vivências e experiências sociais. Ao contrário, consideramos que os corpos são um produto de seu tempo e defendemos que seu ensino não deve estar restrito à disciplina de ciências, nem ao enfoque unicamente biológico.

Ao pensar sobre o espaço e o direcionamento dispensado aos corpos no currículo escolar, é necessário ter em mente que a construção dos currículos é permeada por relações de poder-saber, as quais legitimam quais conteúdos devem estar presentes, qual o direcionamento que deve ser conferido e em que momento. O poder aqui está sendo entendido a partir de Michel Foucault, aquele que "[...] permeia, produz coisas, induz ao prazer, forma saber, produz discurso. Deve-se considerá-lo como uma rede produtiva que atravessa todo o corpo social" (2014, p. 45). Desse modo, entendemos que o poder se estabelece em rede e produz corpos, sujeitos e saberes.

Dentre esses saberes, o saber científico se estabeleceu e se legitimou perante os demais devido ao status de "verdade" que a ciência adquiriu durante os anos. Essa forma de ver a ciência como a reveladora das verdades do mundo dificulta observá-la como uma produção 
humana, suscetível ao questionamento e ao erro. Ao ocupar o lugar de um saber legitimado, a ciência propõe que o corpo no ensino escolar deve ser abordado pelo/a professor/a de ciências e que o enfoque dado ao tema seja a partir do viés biológico.

Nesse sentido, o livro de Mariana foi desenvolvido a partir de interlocuções e diálogos entre os/as integrantes do Grupo de Estudos e Pesquisas em Educação em Ciências - GEPEC, e os/as pesquisadores/as do Instituto de Ciências Biológicas da Universidade Federal do Rio Grande - FURG. E, se a proposta do livro é romper com o ensino dos corpos focado apenas no discurso biológico, buscamos analisar como esse material vêm sendo utilizado nas práticas dos/as docentes. Para tal, realizamos um grupo focal com docentes que vêm produzindo trabalhos com a obra mencionada. Os dados produzidos a partir dessa estratégia estão sendo tomados como dados narrativos, a partir da perspectiva da investigação narrativa, que conduziu a realização dessa pesquisa.

\section{Apresentando os dados narrativos}

A metodologia utilizada para a produção e para a análise dos dados deste trabalho foi a investigação narrativa na perspectiva de Michael Connelly e Jean Clandinin (1995) e Jorge Larrosa (1996, 2011). Estamos tomando como narrativas as falas dos sujeitos durante a realização do grupo focal. A investigação narrativa é uma metodologia de pesquisa de cunho qualitativo, cuja visibilidade vem aumentando nos últimos anos. Entendemos a narrativa como uma prática social que produz os sujeitos. Ao narrar nossa história, acabamos por repensá-la, reconstruí-la e produzi-la, como apontam Paula Ribeiro e Dárcia Ávila (2013):

\footnotetext{
Esse processo de contar histórias vividas faz com que a pesquisa apresente outro olhar, ou seja, esse processo se apresenta como algo complexo porque quando recontamos histórias, não apenas recontamos fatos que aconteceram em outro momento de nossas vidas, mas recontamos essas histórias tal como elas se refletem em nossas experiências presentes. Dessa forma, tanto as histórias como os sentidos que damos a elas, conforme vão sendo recontadas ao longo dos tempos, vão construindo, nos sujeitos, diferentes formas de ver e compreender suas próprias histórias (RIBEIRO; ÁVILA, 2013, p. 72).
}

De acordo com as autoras, nesse movimento de narrar as nossas histórias, passamos a ser construídos por elas. Assim, durante o trabalho com narrativas, não estamos apenas contando as nossas experiências, mas (re)significando a nossa história e impondo significado à experiência. Nossa história é composta por muitas outras que nos foram narradas, como aponta Jorge Larrosa, "a história de nossas vidas depende do conjunto de histórias que temos 
ouvido, em relação às quais temos aprendido a construir a nossa" (1996, p. 461-462). Logo, a narrativa pode ser entendida como uma prática social e cultural que constitui os sujeitos.

Destacamos, também, que no trabalho com as narrativas, o tempo que conta não é o cronológico, dos acontecimentos; a narrativa tem seu tempo próprio, guiado pela ordem em que as lembranças vão surgindo, de forma que podemos perceber um movimento descontínuo de ir e vir. É nesse movimento de narração, nesse ouvir de histórias, que vamos forjando nossa identidade no tempo:

O eu se constitui temporalmente para si mesmo na unidade de uma história. Por isso, o tempo no qual se constitui a subjetividade é tempo narrado. É contando histórias, nossas próprias histórias, o que nos acontece e o sentido que damos ao que nos acontece, que nos damos a nós próprios uma identidade no tempo (LARROSA, 1996, p. 69).

A investigação narrativa permite a utilização de distintas estratégias na produção de dados. Nesta pesquisa, enviamos um questionário para todos/as os/as professores/as de ciências pertencentes à rede municipal de ensino e realizamos um grupo focal com professoras que desenvolveram trabalhos com o livro paradidático da Mariana. Para conhecermos as narrativas desses/as professores/as, primeiramente entramos em contato com a Secretaria de Educação do município, a qual, a partir de um convênio firmado entre a prefeitura do Rio Grande, RS, e a Universidade Federal do Rio Grande - FURG, distribuiu trinta (30) exemplares do livro para cada escola de Ensino Fundamental da cidade. Esse contato com a divisão de bibliotecas visava averiguar se os exemplares haviam sido distribuídos às escolas e como tal processo fora realizado. Nesse contato, fomos informadas de que todos os livros foram entregues às escolas.

Em seguida, buscamos estabelecer contato com as cinquenta e quatro (54) escolas municipais de Ensino Fundamental e conseguimos contatar, por telefone, quarenta e quatro (44), visto que dez (10) escolas pertencem à zona rural do município e não possuem um número de telefone fixo, apenas um celular. Ao contatar esses números, constatamos que alguns já não existiam mais e outros eram direcionados diretamente para a caixa postal. Dessa forma, optamos por trabalhar com quarenta e quatro (44) escolas. Dessas, seis (6) afirmaram não ter conhecimento sobre o material; mesmo após algumas tentativas de contato com diferentes servidores/as da instituição, não conseguimos obter nenhuma informação a respeito do recebimento ou não do livro pela escola. Vinte (20) apontaram que o material não chegou e dezoito (18) afirmaram que o material chegou, sendo que treze (13) estão utilizando o livro.

A partir desse levantamento, passamos a focar nas escolas e nos/as docentes que 
estavam utilizando o material. Para isso, encaminhamos um e-mail para todas as escolas municipais e para os/as professores/as de ciências, posto que o livro foi produzido e direcionado para os/as docentes da disciplina de ciências, os quais receberam um exemplar a fim de que pudessem utilizá-lo em suas práticas. No e-mail, além de uma carta de apresentação da pesquisa, havia um breve questionário com questões dissertativas, que objetivavam conhecer as concepções acerca do livro e como vêm desenvolvendo suas práticas pedagógicas no que diz respeito aos corpos.

Após algumas semanas, recebemos quatro (4) respostas, três (3) foram de docentes da disciplina de ciências, que atuavam em escolas distintas, e uma de um grupo de professoras que estava desenvolvendo um projeto na escola a partir do livro. A fim de conhecer melhor esse projeto, realizamos uma visita à escola, onde ficamos sabendo que o e-mail foi recebido pela coordenadora pedagógica, que organizou, juntamente com docentes, uma resposta coletiva ao questionário. Esse grupo de professoras ${ }^{6}$ desenvolveu um projeto interdisciplinar baseado no livro de Mariana, o que indicou novos caminhos para a nossa pesquisa e possibilitou maior contato com essa escola, o que levou à realização de um grupo focal.

Considerando que o grupo docente da escola mencionada se mostrou receptivo à nossa pesquisa, fomos até a escola. Lá, entramos em contato com a orientadora pedagógica e informamos que gostaríamos de realizar um grupo focal com os/as professores/as que estavam desenvolvendo o projeto de aprendizagem intitulado 15 anos, com o objetivo de perceber os efeitos que a obra vem produzindo nas práticas docentes dessa escola.

O projeto desenvolvido a partir do livro da Mariana é descrito pelas professoras como interdisciplinar, visto que contou com a participação de docentes de distintas áreas, como matemática, português, geografia, literatura, educação artística, ensino religioso, história, ciências e educação física. O projeto teve como fio condutor o livro paradidático e, a partir dele, algumas professoras desenvolveram subprojetos, enquanto outras inseriram a temática em suas práticas, levando em consideração os temas que mais se encaixavam com suas disciplinas.

O desenvolvimento de um projeto de aprendizagem a partir do livro da Mariana foi uma surpresa com a qual nos deparamos durante a realização desta pesquisa. Muitas perguntas sobre a condução desse projeto nos inquietaram e, a fim de conhecer as motivações que o orientaram e os efeitos produzidos pelo livro na prática dessas docentes, realizamos um

${ }^{6} \mathrm{O}$ projeto mencionado foi desenvolvido apenas por mulheres, professoras, assim, ao nos referirmos a este grupo utilizaremos sempre o gênero feminino. 
grupo focal com as que empreenderam a atividade.

Entendemos grupo focal como sendo uma discussão conjunta, realizada com um grupo relativamente pequeno, contendo no máximo doze pessoas, possibilitando, assim, que todos/as possam expressar suas ideias. O grupo conta também com o/a moderador/a, o/a qual é responsável por conduzir as discussões, não precisando ser necessariamente o/a pesquisador/a. De acordo com Sônia Gondim (2003), a ênfase está nos processos psicossociais que emergem, ou seja, no jogo de interinfluências da formação de opiniões sobre um determinado tema, de forma que a unidade de análise do grupo focal é o próprio grupo. O que importa é a opinião do grupo e não a do indivíduo, visto que, durante o processo, os posicionamentos dos sujeitos podem mudar, devido à interação dos sujeitos no grupo, que passam a interferir, questionar e desestabilizar uns aos outros.

Para o desenvolvimento desse grupo focal, contamos com a participação de oito (8) professoras que organizaram e desenvolveram o projeto com as turmas de oitavo ano da escola onde lecionam, a partir do livro da Mariana. Esse encontro ocorreu no local de trabalho das docentes e foi registrado em gravações de vídeo e de áudio ${ }^{7}$. Além das participantes, o grupo era formado pela pesquisadora, que atuou como moderadora, uma colega pesquisadora, que atuou como relatora, e um operador de câmera, que auxiliou nas gravações.

Destaca-se que o grupo focal foi composto por professoras que lecionam as disciplinas de geografia, português, educação física, ensino religioso, literatura, matemática, artes e ciências, e foi realizado durante o horário de trabalho das docentes, sendo-nos cedido o tempo de setenta e cinco minutos para sua realização. No primeiro momento, o grupo se apresentou, contou como foi o contato inicial com o livro, quais as primeiras percepções, como a temática corpo era abordada anteriormente e como surgiu a ideia de desenvolver o projeto. O grupo também contou como o livro foi abordado em cada disciplina, como ocorreu o planejamento do projeto e como se deu a participação dos/as pais/mães e dos/as estudantes nesse processo.

Para a análise dos dados produzidos a partir do grupo focal, utilizamos a estratégia de investigação narrativa. Dessa maneira, as narrativas produzidas pelas professoras em relação ao livro da Mariana foram agrupadas por semelhança, a partir das relações que estabeleciam entre si, e deram origem a dois eixos: impressões dos docentes em relação ao livro e percepção das professoras em relação ao projeto desenvolvido. A seguir, apresentamos as análises.

\footnotetext{
${ }^{7}$ Foi disponibilizado às participantes um Termo de Consentimento para participação na pesquisa.
} 


\section{Analisando as Narrativas de Professoras sobre o livro "Os 15 Anos de Mariana"}

Nesta seção, apresentamos as análises oriundas de dois eixos que emergiram ao longo das narrativas, produzidas durante a realização do grupo focal. Primeiramente, analisaremos as narrativas referentes ao primeiro eixo, que apontam as impressões das docentes em relação ao livro. Como podemos observar, elas destacam a presença de temas que chamam a atenção dos estudantes e a abordagem com que os conteúdos são inseridos ao longo da história.

Sílvia (professora de artes) ${ }^{8}$ - Eu gostei bastante, acho que o livro tem os temas que são bem voltados pra idade deles.

Brisa (professora de geografia) - Eu achei ele um livro bastante eclético, bem voltado pra idade deles mesmo.

Rose (professora de ciências) - Eu gostei bastante do livro porque tem os conteúdos, que a gente se preocupa um pouco com esse lado também, mas de uma forma, assim, literária, de uma forma que agrada o adolescente, os assuntos, a questão familiar uma série de coisas.

Gabriela (professora de ensino religioso) - Eu já conhecia o livro 15 anos de Mariana, pra mim os assuntos são excelentes, é bem dentro do que eu trabalho, então foi bem confortável.

Juliana (professora de educação física) - Eu acho que o livro em si como as gurias disseram, pra mim ele traz... ele é bem pertinente nas coisas que eles passam, que eles precisam saber e que eles gostam de falar.

A partir das narrativas apresentadas, apontamos que o livro da Mariana foi bem acolhido pelos/as professores/as nas escolas, especialmente por apresentar temas que são direcionados para a idade dos/as estudantes. Ressalta-se que esse projeto ${ }^{9}$ foi desenvolvido com turmas de oitavo ano do Ensino Fundamental, sendo quatorze (14) anos a idade, em média, desses/as estudantes, o que os/as classifica como adolescentes, segundo o Estatuto da Criança e do Adolescente (BRASIL, 2012), que demarca a adolescência como o período dos doze (12) aos dezoito (18) anos de idade. Assim, podemos inferir que, para esse grupo de professoras, os temas abordados no livro, como corpo, sexualidade, consumo de álcool e

${ }^{8}$ Os nomes apresentados aqui são fictícios e foram escolhidos pelas próprias participantes.

${ }^{9} \mathrm{O}$ projeto aqui mencionado foi desenvolvido por docentes de distintas disciplinas que lecionam nos oitavos anos e tinha como base o livro de Mariana. 
problemas familiares, fazem parte do universo adolescente.

Consideramos que a adolescência não é uma fase "natural" da vida, mas uma produção carregada de significados culturais, históricos e sociais,

[...] uma construção que se dá a partir dos discursos de diversos campos biologia, psicologia, sociologia, história, antropologia, entre outros - e de diversas pedagogias culturais - programas de TV, jornais, revistas, músicas, propagandas, filmes, festas, etc. - que, ao representarem a adolescência, estão indo além de dizer ou mostrar o que é ser adolescente, estão ativamente produzindo essa etapa da vida (QUADRADO, 2006, p. 28).

Atentar para o carácter produzido dessa fase descrita como adolescência possibilita reconhecer que ela não é fixa, estável, universal. Isso aponta que nem todos/as vivenciaram as mesmas experiências na mesma idade, o que nos levar a afirmar que existem múltiplas formas de ser adolescente, como aponta Suzana Barros: "não podemos afirmar que todos/as adolescentes são irritantes, confusos, gostam de aparecer e vivenciam a sexualidade" (2014, p. 26). Entretanto, destacamos que no documento da Base Nacional Comum Curricular ${ }^{10}$ (BRASIL, 2017) a adolescência vem sendo pensada somente a partir do discurso científico, ao propor que, ao nono ano do ensino fundamental, sejam abordadas as mudanças que acontecem na adolescência, focando nas doenças sexualmente transmissíveis e nas transformações físicas e emocionais.

O direcionamento proposto nesse documento contribui para sustentar um discurso que aponta a adolescência como uma época marcada pela biologia, em que é necessário conhecer o próprio corpo para melhor gerenciá-lo. Esse enfoque legitima o discurso de que o corpo deve ser abordado nos oitavos anos, pois nessa idade os estudantes já estão maduros para falar sobre o tema, como podemos observar nas narrativas das professoras ao serem indagadas sobre a utilização do livro com outras turmas.

Dana (professora de português) - A sexualidade seria no $8^{\circ}$ ano, pensando em outras séries, outros anos não.

Rose - É se trabalha questões desde que eles são pequenos, mas assim, o foco principal é no $8^{\circ}$ ano.

Dana - Até pela maturidade.

Dana - Eu acho interessante, a história da camisinha, do pênis de

${ }^{10}$ Documento em fase de análise pelo Conselho Nacional de Educação (CNE), que pode ser acessado na página http://basenacionalcomum.mec.gov.br/\#/site/inicio. 
borracha eu acho muito interessante, porque pra idade deles, é da idade deles, eles têm que aprender, eles têm que saber eu acho importante.

As narrativas apresentadas indicam um receio em trabalhar um livro que discute a produção dos corpos fora do espaço que o currículo legitima como pertencente ao corpo, ou seja, o oitavo ano do Ensino Fundamental. Essa resistência em pensar o corpo fora do oitavo ano não é uma questão restrita a ciências, como podemos observar na narrativa da professora de matemática, que aponta ter enfrentado dificuldades em se encaixar no projeto:

Lica (professora de matemática) - Esse foi o problema, os conteúdos do oitavo ano não me deixaram entrar muito no projeto, então esses conteúdos mesmo de gráficos, claro a gente tem que trabalhar sempre, mas não é um conteúdo do oitavo ano, é mais do nono, lá do sexto ano e depois do nono ano.

Essa "tradição" curricular que aponta quais conteúdos devem estar presentes no currículo, a partir de qual viés devem ser abordados e em qual ano, necessita ser problematizada. Para tal, devemos lembrar, como aponta Santos (2004), que a ciência possui uma história que está longe de ser natural. Ela deve ser encarada como uma produção que carrega suas marcas. Como uma narrativa, cujas "histórias produzem seres materiais muito específicos e que a forma como se fala deles não só os descreve, mas os produz" (SANTOS, 2004, p. 254).

A dificuldade em incluir a Matemática em projetos interdisciplinares por vezes encontra-se centrada na forma em que essa ciência é vista, ou seja, como uma área do conhecimento responsável por trabalhar com números e abstrações. Entretanto, essa visão simplista e frágil sobre a Matemática necessita ser repensada, como aponta Isabel Lara:

Esse "bicho-papão" ou terror dos/as nossos/as alunos/as só perderá sua áurea de "lobo-mau" quando nós, educadores/as, centrarmos todos os nossos esforços para que ensinar Matemática seja: desenvolver o raciocínio lógico e não apenas a cópia ou repetição exaustiva de exercícios-padrão; estimular o pensamento independente e não apenas a capacidade mnemônica; desenvolver a criatividade e não apenas transmitir conhecimentos prontos e acabados; desenvolver a capacidade de manejar situações reais e resolver diferentes tipos de problemas e não continuar naquela "mesmice" que vivemos quando éramos alunos/as (LARA, 2003, p. 18-19).

Então, o entendimento de que o conhecimento matemático se encontra inserido em nosso cotidiano possibilitará olhar para esse saber de outra maneira. Dessa forma, sua 
articulação com as demais disciplinas poderá ser mais efetiva, o que pode contribuir para que o/a estudante construa "uma prática educativa capaz de promover a troca de experiências matemáticas com outras disciplinas, viabilizando a compreensão dessa em relação a seus campos de aplicação" (SILVA; GROENWALD, 2001, p. 169).

Entendemos que o lugar ocupado pelos conteúdos no currículo escolar é um lugar construído em meios a relações de poder-saber, as quais estabeleceram o discurso científico como o saber legitimado para conduzir as discussões. Em relação a essa legitimidade adquirida pelo saber científico, Luís Henrique dos Santos aponta:

[...] havia (e há) a crença de que a ciência seria (é) o privilegiado meio de "desvelar a realidade" do mundo. Como meio indiscutível de "desvelamento" do mundo não é de se estranhar que a escola tenha adotado de forma irrestrita e acrítica as especificidades ditadas por aqueles que estavam (e estão) fazendo ciência. Nesse sentido, se investem de maior poder explicativo, para dizer como deve ser o ensino de ciências, precisamente, aquelas propostas que se fundamentam nas ciências de origem (química, física, biologia - as ditas hard sciences/ciências duras). Tais propostas ganham legitimidade no campo do ensino em ciências, justamente, por se constituírem em traduções/imitações das ciências de origem. (SANTOS, 2004, p. 230-231, grifos do autor)

A partir do exposto, podemos entender como os saberes da ciência adquiriram um lugar legitimado no currículo. Assim, cabe problematizar os demais discursos envolvidos na produção dos corpos e questionar por que determinados conteúdos estão entrelaçados a séries específicas.

O segundo eixo de análise reúne as narrativas referentes às percepções das professoras sobre o projeto desenvolvido. De acordo com as docentes, sua realização agradou muito os/as estudantes, como podemos observar nas narrativas expostas:

Rose - A partir do tema, cada tema do livro, eles tiravam mais alguma coisa que eles tinham curiosidade, a partir daquilo ali então abria o leque, nós aprofundamos a questão do livro.

Dana - Eu acho que no livro aparece o álcool, não cita as drogas ilícitas. Mas eles puxaram, eles queriam saber se podia e eu disse que podia, falava das lícitas e puxava as ilícitas, e eles puxaram, eles perguntaram e eu deixei.

Rose - Eu perguntava: mas por que que tu escolheu isso? Não, eu queria saber sobre isso. Assim realmente partiu da curiosidade deles, isso que eu acho importante. 
As narrativas indicam que o desenvolvimento do projeto mobilizou os/as estudantes a pesquisarem temas que estão presentes no cotidiano deles/as e que, muitas vezes, não encontram espaço para serem discutidos no ambiente escolar. Como apontam Cunha, Freitas e Silva (2010), ao abordarmos a temática do corpo humano, não podemos focar somente nos aspectos fisiológicos; é necessária uma abordagem que considere temas como a gravidez na adolescência, as doenças sexualmente transmissíveis, boa alimentação, exercícios físicos, obesidade, bulimia, bullying e agressões ao corpo. Todos estes temas devem estar em nossas preocupações.

Ao desenvolver o projeto 15 anos, as professoras passaram a trabalhar com os conhecimentos que os/as estudantes já possuíam e, a partir das suas inquietações e curiosidades, eles foram incentivados a pesquisar sobre os temas que gostariam de conhecer mais. Como nos conta a professora Brisa, ao narrar que os/as estudantes saíram de sua zona de conforto e foram buscar informações sobre assuntos de seu interesse em livros, na internet e no posto de saúde:

Brisa - Motiva também o aluno a procurar, como foi o trabalho das gurias sobre sexualidade. Eles foram além, pesquisaram outras coisas. Quanta coisa, quanto conhecimento a gente conseguiu adquirir em cima do livro, de um livro interessante.

Rose - Ah e eles encontraram na internet uma informação errada e eles souberam depois corrigir, isso eu gostei, também.

Juliana - O livro fala de sexualidade de uma forma mais... claro, ele entra no assunto da ciência, mas ela fala de uma forma mais superficial e aí o grupo ia lá e pesquisava geralmente o que eles queriam saber além do livro.

A partir dessa interação, professoras e estudantes passam a construir outro conhecimento, que é interessante, tem significado e pode ser aplicado de forma prática no cotidiano. Ao se questionarem sobre como o conteúdo pedagógico afetava a curiosidade do/a estudante, e, a partir disso, incentivarem seus/as estudantes a pesquisarem e a elaborarem novas perguntas (BRITZMAN, 2013), esse grupo de professoras possibilitou que eles/as se sentissem mais à vontade para perguntar e discutir qualquer tema no ambiente escolar, como apontam as narrativas das professoras Rose e Sílvia.

Rose - Tem aprendizagens que eles não se deram conta que fizeram. 
Sílvia - Eles estavam confortáveis com uma coisa que rodeia a vida deles. Algumas vezes, a gente faz um projeto e eles sabem tudo sobre o projeto, embora a gente saiba que eles já sabem muita coisa, aprendem muita coisa, mas eles falam meio que a parte do que eles aprenderam, mas não é o que eles vivenciam e ali não. Ali eles estavam bem à vontade.

Atualmente, com tantos atrativos, como internet e programas de televisão, tornar a escola atrativa não tem sido uma tarefa muito fácil, visto que "os currículos organizados pelas disciplinas tradicionais, da forma como vêm sendo desenvolvidos, conduzem o aluno apenas a um acúmulo de informação que de pouco ou nada valerão na sua vida profissional" (FAZENDA, 1997, p. 155). Entretanto, podemos dizer que as atividades desenvolvidas por esse grupo de professoras possibilitaram que os/as estudantes produzissem não um conhecimento mecânico, o qual tem como objetivo final uma prova, mas conhecimentos que estabelecem relações e fazem sentido para o/a estudante, pois partem das suas inquietações, das suas curiosidades. Nesse sentido, o desenvolvimento das atividades deve ser pautado nas problemáticas "para as quais os alunos querem respostas, e não somente em torno das perguntas e respostas encontradas no livro didático. As aulas devem ser fomentadas pela discussão em torno de curiosidades cotidianas" (CUNHA; FREITAS; SILVA, 2010, p. 70).

A partir das narrativas das professoras, entendemos que esse projeto mobilizou os/as estudantes. Eles/as se sentiram confortáveis para perguntar, discutir, procurar outras fontes de informação, pois estavam envolvidos/as com os temas abordados. Assim, para esse grupo foi possível experimentar um currículo que não se centra apenas no ensinar, mas que considera as distintas formas de aprendizagem, buscando incorporar em suas discussões aspectos didáticos, culturais, históricos e políticos. Dessa forma, o que move esse currículo é "o prazer de ensinar junto com a alegria do aprender" (PARAÍSO, 2015, p. 283).

\section{Algumas considerações}

As narrativas apresentadas apontam que o livro "Os 15 anos de Mariana: um convite a outras aprendizagens sobre corpos" vem produzindo efeitos nas práticas pedagógicas dessa escola do município do Rio Grande, RS. Entre os efeitos produzidos, destacamos o engajamento de professoras e estudantes na concepção e no desenvolvimento de um projeto interdisciplinar, baseado no livro. O projeto desafiou as docentes a abordarem a produção dos corpos nas disciplinas que lecionam e tornou o ambiente escolar mais interessante para os/as 
estudantes, pois abordou temas com os quais estavam familiarizados, tais como as mudanças dos corpos, bullying, sexualidade, entre outros.

As narrativas produzidas pelas professoras demonstram que o livro foi bem aceito pela comunidade escolar. Entre os pontos destacados, estão a temática abordada na obra, que estabelece relação com o dia-a-dia dos/as estudantes, e o fato de o livro apresentar os conteúdos de ciências relativos ao corpo humano de uma maneira lúdica e divertida, a qual agrada aos/às alunos/as. As docentes também reafirmam o discurso de que a temática do corpo deve ser restrita ao oitavo ano, afirmando que os/as estudantes menores não possuem maturidade para abordar tal tema e, no ano seguinte, os temas são outros. Dessa forma, ainda que a atividade tenha propiciado algumas rupturas na maneira de perceber o ensino dos corpos, ainda estamos presos/as à estrutura conteúdo/série. Aponta-se que esse fato não se restringe ao conteúdo corpo humano, pois a professora de matemática afirma ter tido dificuldades no desenvolvimento do projeto, posto que os temas abordados no oitavo ano não estabeleciam relação com o livro. Nesse sentido, entendemos que ainda existe um lugar "certo" e pré-determinado para abordar cada assunto e esse lugar é dado através da organização curricular, do livro didático e das docentes, que acabam por seguir tais documentos.

Apesar das limitações, as atividades propostas, de acordo com as docentes, suscitaram a curiosidade dos/as estudantes, mobilizando-os a pesquisarem outras temáticas que não haviam sido discutidas em sala de aula. Assim, tal abordagem possibilitou o desenvolvimento de uma aprendizagem prazerosa, ancorada nas experiências dos/as estudantes. Logo, entendemos que compreender a ciência e o currículo escolar como produções históricas, políticas e culturais, imersas em relações de poder-saber, pode constituir um caminho para podermos pensar outras formas de ensino e de aprendizagem. O livro "Os 15 de Mariana: um convite a outras aprendizagens sobre corpos", ao propor uma abordagem distinta da encontrado no livro didático, possibilita brechas para que outras formas de organização do trabalho docente emerjam, possibilitando que outras formas de se pensar o corpo no currículo escolar ganhem espaço nas práticas docentes.

\section{REFERÊNCIAS}

BARROS, S. C. de. Sexting na adolescência: análise da rede de enunciações produzida pela mídia. 2014. 188f. Tese. Doutorado. Programa de Pós-graduação em Educação em Ciências: Química da Vida e Saúde. Universidade Federal do Rio Grande, Rio Grande, 2014. 
BRASIL. Base Nacional Comum Curricular. Brasília, 2017. Disponível em http://basenacionalcomum.mec.gov.br/a-base. Acesso em: 15 mar. 2017.

BRASIL. Estatuto da criança e do adolescente: Lei federal nº 8069, de 13 de julho de 1990. 9. ed. Brasília, 2012.

BRITZMAN, D. Curiosidade, sexualidade e currículo. In: LOURO, G. L. (Org.) O corpo educado: pedagogias da sexualidade. Belo Horizonte: Autêntica Editora, 2013.

BRUNS, M. A. de T.; DAVI, E. H. D. Travestis: corpos em trânsito!? Sonho, mito e realidade. Revista Ibero-americana de Estudos em Educação. Araraquara, v. 11, n. esp. 1, p. 434-444, 2016. Disponível em: http://seer.fclar.unesp.br/iberoamericana/article/view/8564 Acesso em: 19 jun. 2016.

CONNELLY, M.; CLANDININ, J. Relatos de experiencia e investigación narrativa. In: LARROSA, J. et al. Déjame que te cuente: ensayos sobre narrativa y educación. Barcelona: Laertes, 1995.

CUNHA, A. M. de O.; FREITAS, D.; SILVA, E. P. de Q. O corpo da ciência, do ensino, do livro e do aluno. In: PAVÃO, A. C. (Coord.) Coleção Explorando o Ensino. Ciências: ensino fundamental. v. 18. Brasília: Ministério da Educação, Secretaria de Educação Básica, 2010 .

FAZENDA, I. C. A. Reflexões Metodológicas sobre a tese: interdisciplinaridade - um projeto em parceria. In: FAZENDA, I. C. A. (Org.) Metodologia da pesquisa educacional. 4. ed. São Paulo: Cortez, 1997.

FOUCAULT, M. Verdade e Poder. In: FOUCAULT, M. Microfísica do poder. 28. ed. Rio de Janeiro: Paz e Terra, 2014.

GONDIM, S. G. Grupos focais como técnica de investigação qualitativa: desafios metodológicos. Paidéia: Cadernos de Psicologia e Educação, Ribeirão Preto, v. 12, n. 24, p. 149-161, 2003.

LARA, I. C. M. de. Jogando com a Matemática de 5a a 8ª́rie. São Paulo: Rêspel, 2003.

LARROSA, J. Narrativa, identidad y desidentificación. In: LARROSA, J. La experiencia de la lectura. Barcelona: Laertes, 1996.

LARROSA, J. Tecnologias do Eu e educação. In: SILVA, T. T. da. O Sujeito da educação: Estudos Foucaultianos. 8. ed. Petrópolis: Vozes, 2011.

LOURO, G. L. Pedagogias da sexualidade. In: LOURO, G. L. (Org.). O corpo educado: pedagogias da sexualidade. 3. ed. Belo Horizonte: Autêntica, 2013.

MOREIRA. A. F. B.; SILVA. T. T. da. Sociologia e teoria crítica do currículo: uma introdução. In: MOREIRA. A. F. B.; SILVA. T. T. da. (Org.). Currículo, cultura e sociedade. São Paulo. Cortez, 2000. 
PARAÍSO, M. A. Currículo nômade: quando os devires fazem a diferença proliferar. In: KIRCHOF, E. R.; WORTMANN, M. L.; COSTA, M. V. (Org.) Estudos Culturais e Educação: contingências, articulações, aventuras, dispersões. Canoas. Ed. da Ulbra, 2015.

QUADRADO, R. P. Adolescentes: Corpos inscritos pelo gênero e pela cultura de consumo. 129f. Dissertação. Mestrado. Programa de Pós-Graduação em Educação Ambiental. Universidade Federal do Rio Grande - FURG. Rio Grande, 2006.

RIBEIRO, P. R. C.; ÁVILA, D. A. Sujeitos, histórias, experiências, trajetórias...a narrativa como metodologia na pesquisa educacional. In: SILVA, G. R.; HENNING, P. C. (Org.). Cadernos Pedagógicos, Pesquisas em Educação: experimentando outros modos investigativos - Rio Grande. Editora da FURG, 2013.

SANTOS, L. H. S. A biologia tem uma história que não é natural. In: COSTA, M. V.; VEIGA-NETO, A. (Org.). Estudos culturais em educação: mídia, arquitetura, brinquedo, literatura, cinema... Porto Alegre. Editora da Universidade UFRGS, 2004.

SILVA, C. K. Da.; GROENWALD, L. O. Integrando a Matemática ao tema Educação Ambiental. Paradigma. Maracay, v. XXII, n. 2. 2001. Disponível em: http://revistas.upel.edu.ve/index.php/paradigma/article/view/2962/1388. Acesso em: 8 mar. 2016.

SILVA, E. P. de Q. A invenção do corpo e seus abalos: diálogos com o ensino de Biologia. 2010. 202f. Tese. Doutorado. Programa de Pós-graduação em Educação. Universidade Federal de Uberlândia, Uberlândia, 2010.

\section{Como referenciar este artigo}

CHIMIESKI, T. G.; QUADRADO, R. P. Analisando narrativas sobre a utilização do livro "os 15 anos de mariana" em uma escola municipal do rio grande, rs. Revista Ibero-Americana de Estudos em Educação, Araraquara, v. 14, n. 1, p. 77-93, jan./mar., 2019. E-ISSN: 19825587. DOI: $10.21723 /$ riaee.v14i1.8784

Submissão: $17 / 09 / 2016$

Revisões requeridas: 25/04/2017

Aprovação final: 05/11/2017 